\title{
Linking care of patients with obesity to outpatient weight control clinics following acute hospitalizations
}

This article was published in the following Dove Press journal:

Diabetes, Metabolic Syndrome and Obesity:Targets and Therapy

\author{
Ché M Harris' \\ Lawrence J Cheskin² \\ Trina L Gipson-Jones ${ }^{3}$ \\ Jennifer A Hartfield ${ }^{4}$ \\ Flora Kisuule \\ 'Division of General Internal \\ Medicine, Johns Hopkins School of \\ Medicine, ${ }^{2}$ Department of Health, \\ Behavior and Society, The Johns \\ Hopkins Bloomberg School of Public \\ Health, The Johns Hopkins University, \\ Baltimore, MD, USA; ${ }^{3}$ School of \\ Nursing, Hampton University, \\ Hampton, VA, USA; ${ }^{4}$ Center for \\ Research on Men's Health, Vanderbilt \\ University, Nashville, TN, USA
}

Correspondence: Ché M Harris Johns Hopkins Bayview Medical Center, 5200 Eastern Avenue, Baltimore, MD 21224, USA

Tel +l 4105505018

Fax + I 4I0 5502972

Email charri21@jhmi.edu

\begin{abstract}
Despite obesity impacting over one-third of US adults, guideline recommendations have not been effectively utilized by health care providers in hospital settings. Initiation of weight loss plans for obese patients during hospitalizations followed by linkage of care to weight control centers may improve compliance with the guidelines. Provider recognition and awareness that obesity is a chronic condition that warrants inpatient counsel and management with appropriate arrangement of postdischarge follow-up care will be critical to guideline implementation. Keywords: guideline compliance, health systems, intervention, linkage
\end{abstract}

The obesity epidemic affects more than one-third of US adults, ${ }^{1}$ and in 2013 , contributed to 342 billion dollars in direct health care costs. ${ }^{2}$ In 2013, the American Heart Association/American College of Cardiology (AHA/ACC) Task Force on Practice Guidelines and The Obesity Society (TOS) published guidelines recommending providers "prescribe on site high intensity weight loss interventions provided in individual or group sessions by trained interventionists." benefits greatly outweigh risks, and the procedure or treatment should be performed. ${ }^{3}$ Research has found that physician referrals to weight loss clinics are beneficial. ${ }^{4}$ However, implementation of guidelines following hospitalizations has been underexplored. Closing this gap provides a relatively untapped opportunity for inpatient health care providers to improve patient outcomes following discharge to home. Specifically, linking motivated patients with obesity to weight control clinics may lead to improvement in health for some of the sickest patients who just experienced an acute hospitalization.

In addition, the AHA/ACC and TOS recommends a "prescription for face to face or telephone delivered weight management programs that provide regular contact (monthly or more frequent) with interventionists." Although obesity may not be the chief reason for hospitalization in many patients, it is a chronic issue and major contributor to health risks that warrants attention. For comparison, if a patient admitted with pneumonia also had chronic "stable" medical issues, such as hypertension, HIV, or diabetes, it is imperative that these chronic illnesses also be optimally managed during that hospitalization. Failure to address chronic medical conditions during hospitalizations may result in adverse short- or long-term consequences.

Linkage to care following hospitalizations for some chronic medical conditions is recommended (Table 1) ${ }^{5,6}$ For instance, the American Diabetes Association (ADA) officially recommends that all patients with hyperglycemia have follow-up with a primary care provider, endocrinologist, or diabetes educator within 1 month of discharge 
Table I Recommendations for ongoing medical care of chronic diseases after hospitalizations

\begin{tabular}{|c|c|}
\hline $\begin{array}{l}\text { Chronic medical } \\
\text { illness }\end{array}$ & Recommendations on linkage to care following hospitalizations \\
\hline Atrial fibrillation & $\begin{array}{l}\text { Society of Cardiovascular Patient Care }(2013)^{12} \\
\text { At discharge, either from the ED or an acute care facility, patients with atrial fibrillation should be provided with near-term } \\
\text { (e.g., within I week) outpatient follow-up with either a generalist or a specialist. Even in the patient initially requiring minimal } \\
\text { medical therapy, postdischarge assessment could obviate future ED visits due to symptoms brought on by resuming normal } \\
\text { activity. }\end{array}$ \\
\hline COPD & $\begin{array}{l}\text { European Respiratory Society/American Thoracic Society guideline }(2017)^{13} \\
\text { For patients who are hospitalized with a COPD exacerbation, initiation of pulmonary rehabilitation is recommended within } 3 \\
\text { weeks after hospital discharge. }\end{array}$ \\
\hline Diabetes mellitus & $\begin{array}{l}\text { American Diabetes Association }(2018)^{6} \\
\text { An outpatient follow-up visit with the primary care provider, endocrinologist, or diabetes educator within I month of } \\
\text { discharge is advised for all patients having hyperglycemia in the hospital. Clear communication with outpatient providers either } \\
\text { directly or via hospital discharge summaries facilitates safe transitions to outpatient care. Providing information regarding the } \\
\text { cause of hyperglycemia (or the plan for determining the cause), related complications and comorbidities, and recommended } \\
\text { treatments can assist outpatient providers as they assume ongoing care. }\end{array}$ \\
\hline Heart failure & $\begin{array}{l}\text { American Heart Association }(2015)^{14} \\
\text { Early office follow-up within first week of discharge. Very early postdischarge contact and communication with patient and/or } \\
\text { care provider. }\end{array}$ \\
\hline Hypertension & $\begin{array}{l}\text { Franklin MM, McCoy MA }(2017)^{5} \\
\text { Consideration for transition coaches to assist with medications and follow-up. }\end{array}$ \\
\hline
\end{tabular}

Abbreviations: COPD, chronic obstructive pulmonary disease; ED, emergency department.

from the hospital. ${ }^{6}$ In the United Kingdom, the Joint British Diabetes Society for Inpatient Care developed guidelines for safe discharge of patients with diabetes. ${ }^{7}$ Also patients hospitalized with heart failure have reduced mortality and readmissions if they follow-up in heart failure clinics. ${ }^{8}$ Future US obesity guidelines may build on these examples that emphasize postdischarge care. Patients who follow-up in weight control clinics can be assessed by clinicians who can determine their readiness and ability to start guidelinerecommended high-intensity weight loss plans. Such clinics will be well suited to provide follow-up with patients for dietary and exercise counsel, behavioral assessments, weight checks, and motivational support.

There were over 3 million admissions in 2009 for obesity or its related comorbidities ${ }^{9}$; however, arranging linkage to care, focused on weight control posthospitalization, has not been a major health care focus. This might be because of barriers, and factors that may hinder linkage to care include: 1) lack of community weight loss resource facilities; 2 ) restrictions or absence of insurance coverage for outpatient weight loss care; 3) dropped communication between the discharging inpatient facility with the patient and/or the patient's primary care provider; 4) lack of provider knowledge about available resources and/or how to link patients to care; 5) ongoing physical or mental illnesses that preclude immediate safe exercise or weight loss efforts; 6) social barriers, such as homelessness, lack of transportation or social support, and challenging living arrangements; and 7) patient unwillingness to comply with treatment recommendations. Each of these barriers may be circumvented through coordinated team efforts and close communication with the patient and those who will assume care for weight loss interventions after discharge.

Increased attention should focus on early recognition of patients who are obese to help hospitals and inpatient providers meet recommended obesity guideline goals and improve patient outcomes. Early discharge planning allows time to link patients to outpatient weight loss services and address potential barriers. An aggressive inpatient multidisciplinary approach involving case managers, social workers, clinical nutritionists, physical therapists, nurses, and physicians is crucial to ensure that patients with obesity have uninterrupted transitions of care to outpatient weight control clinics. In places without local weight loss facilities, communication between inpatient providers and outpatient primary care doctors may help patients stay focused on weight loss plans even in the absence of linkage to formal weight control programs. Weight loss efforts can start by actively engaging patients during hospitalizations and discussing weight loss target goals and barriers before discharge. Harris et a ${ }^{10}$ described that many hospitalized patients with obesity welcome inpatient initiated weight loss interventions. Patients most receptive to interventions were those who recognized being obese and believed that weight loss would lead to improved health. Furthermore, these patients wanted their outpatient providers to be made aware of weight loss plans initiated in the hospital. ${ }^{10}$ This patient population would most likely benefit from linkage to care, as their motivation for change appears 
strong. In addition, for our most vulnerable patients (e.g., the uninsured or those who are not necessarily motivated to lose weight), hospitalizations may represent the only encounter with a provider who can begin to address obesity and weight loss options. ${ }^{11}$

We consider obesity a public health emergency that has led to devastating increases in death rates, morbidity, and health care costs. Despite expert development and promulgation of obesity guidelines for health care practitioners to follow, enacting these recommendations has not been extensively explored. Linking patients to weight control clinics after hospitalizations can help hospitals and their care providers meet these Class I recommendations. Hospitalizations are often critical times in patients' lives where they reflect and learn more about their general health and medical conditions. Inpatient providers can take these opportunities to teach patients about the importance of weight loss in association with improved body composition and expected cardiovascular benefits. As such, a hospital experience can be mobilized and used as an additional tool in the armamentarium to combat obesity. We recommend that inpatient providers make specific efforts to diagnose, manage, and provide discharge planning for obesity as they would any other chronic medical disease encountered during routine hospitalizations.

\section{Current knowledge}

- Health care providers do not routinely address obesity and weight loss strategies.

- Obesity guidelines are underutilized by health care providers.

\section{Contribution to the literature}

- Linking patients to weight control centers after hospital discharge may improve weight loss goals and patient outcomes.

- Linking patients to weight control clinics following hospitalizations may help providers and hospitals to meet recommended obesity guidelines.

- This perspective piece addresses opportunity for providers to engage with hospitalized patients and help with initiation of long-term weight loss strategies.

\section{Acknowledgments}

This study was supported by a grant from the National Heart, Lung, and Blood Institute to the University of Mississippi Medical Center (1R25HL126145-01 - MPI-Dr. Bettina Beech, DrPH, MPH; Dean, Bower School of Population Health; The University of Mississippi Medical Center,
Jackson, MS, USA. Dr. Keith Norris, MD, PhD; Ronald Reagan University of California, Los Angeles Medical Center, Los Angeles, CA, USA).

\section{Author contributions}

All authors contributed toward data analysis, drafting and revising the paper and agree to be accountable for all aspects of the work.

\section{Disclosure}

Dr. Lawrence J Cheskin is a founder and director of the Johns Hopkins Weight Management Center and is Chair of the Scientific Advisory Board of Medifast, Inc. The other authors report no conflicts of interest in this work.

\section{References}

1. Centers for Disease Control and Prevention [webpage on the Internet]. Adult Obesity Facts. Available from: https://www.cdc.gov/obesity/data/ adult.html. Accessed November 6, 2017.

2. Biener A, Cawley J, Meyerhoefer C. The high and rising costs of obesity to the US health care system. J Gen Intern Med. 2017;32(Suppl 1):6-8.

3. Jensen MD, Ryan DH, Apovian CM, et al. 2013 AHA/ACC/TOS guideline for the management of overweight and obesity in adults: a report of the American College of Cardiology/American Heart Association Task Force on Practice Guidelines and The Obesity Society. Circulation. 2014;129(25 Suppl 2):S102-S138.

4. Binks M, O'Neil MP. Referral sources to a weight management program. J Gen Intern Med. 2002;17(8):596-603.

5. Franklin MM, McCoy MA. The transition of care from hospital to home for patients with hypertension. Nurse Pract. 2017;42(2):12-18.

6. American Diabetes Association. Diabetes care in the hospital: standards of medical care in diabetes-2018. Diabetes Care. 2018;41(Suppl 1):S144-S151.

7. Jairam C, Waldern E, Dornhorst A; Joint British Diabetes Societies for Inpatient Care. Discharge Planning for Adult Inpatients with Diabetes; 2015. Available from: http://www.diabetologists-abcd.org.uk/JBDS/ JBDS_Discharge_Planning_Final_2015.pdf. Accessed January 11, 2018.

8. Howlett JG, Mann OE, Baillie R, et al. Heart failure clinics are associated with clinical benefit in both tertiary and community care settings: data from the Improving Cardiovascular Outcomes in Nova Scotia (ICONS) registry. Can J Cardiol. 2009;25(9):e306-e311.

9. Wess AJ, Elixhauser A. Obesity-Related Hospitalizations, 2004 versus 2009: Statistical Brief \#137. Healthcare Cost and Utilization Project (HCUP) Statistical Briefs [Internet]. Rockville, MD: Agency for Healthcare Research and Quality (US); 2006-2012.

10. Harris CM, Rios R, Landis R, Khaliq W, Wright S. Receptivity to weight management interventions among hospitalized obese patients: an untapped opportunity. South Med J. 2013;106(6):337-342.

11. Kisuule F, Minter-Jordan M, Zenilman J, et al. Expanding the roles of hospitalists to include public health. J Hosp Med. 2007;2(2):93-101.

12. Steinberg BA, Beckley PD, Deering TF, et al. Evaluation and management of the atrial fibrillation patient: a report from the Society of Cardiovascular Patient Care. Crit Pathw Cardiol. 2013;12(3): 107-115.

13. Wedzicha JA, Miravitlles M, Hurst JR, et al. Management of COPD exacerbations: a European Respiratory Society/American Thoracic Society guideline. Eur Respir J. 2017;49(3):1600791.

14. Abert NM, Barnason S, Deswal A, et al. Transitions of care in heart failure: a scientific statement from the American Heart Association. Circ Heart Fail. 2015;8(2):384-409. 
Diabetes, Metabolic Syndrome and Obesity: Targets and Therapy is an international, peer-reviewed open-access journal committed to the rapid publication of the latest laboratory and clinical findings in the fields of diabetes, metabolic syndrome and obesity research. Original research, review, case reports, hypothesis formation, expert opinion and commentaries are all considered for publication. The manuscript management system is completely online and includes a very quick and fair peer-review system, which is all easy to use. Visit http://www.dovepress.com/testimonials.php to read real quotes from published authors.

Submit your manuscript here: https://www.dovepress.com/diabetes-metabolic-syndrome-and-obesity-targets-and-therapy-journal 